\title{
PENGARUH IMPLEMENTASI EXPERIENTIAL MARKETING TERHADAP LOYALITAS MEMBER SALON HUMAIRA
}

\author{
Christianingrum \\ Universitas Bangka Belitung \\ Syifa.meira@yahoo.com
}

\begin{abstract}
The Development beauty salon industry to grow and properly. Application of the right strategies will be able to retain customers in order to remain defended and loyal to the company in this industry, particularly the Muslim salon. Local customers benefit the company. One effort to keep customers loyal was provided the best deals for consumers, such as giving a unique and memorable experience to customers on every transaction made.

This study was conducted to analyze and describe experiential marketing, loyalty in the salon Humaira picture and know how big the influence of experiential marketing to loyalty members Humaira salon. Respondents in this study are members Humaira Tubagus Ismail Beautiful salon. The method used in this research is explanatory survey and descriptive survey. The data used are primary data and secondary data collected through observation, literature study and questionnaire. The hypothesis of this study was " if the application of experiential marketing is good, then the high customer loyalty," it was tested using path analysis.

Results of this research explained that experiential marketing as measured by the dimension of sense, feel, think, act and relate. They were had a positive influence and significant impact on customer loyalty, the overall value of t obtained through the analysis of pathways is greater than t table means the better implementation of experiential marketing Salon Humaira, the higher their loyalty to the salon Humaira.
\end{abstract}

Keywords: Experiential Marketing, Loyalty

\section{PENDAHULUAN}

\subsection{Latar Belakang Penelitian}

Kesuksesan suatu bisnis tergantung pada ide, peluang dan pelaku bisnis. Pelaku bisnis harus mampu menciptakan ide-ide baru agar dapat memberikan nilai lebih (value) kepada konsumen. Selain itu pelaku bisnis juga harus mampu untuk melihat peluang bisnis yang berkembang. Salah satu bisnis yang sedang berkembang saat ini adalah bisnis kecantikan atau sering dikenal dengan istilah salon.

Salon adalah salah satu bidang jasa yang tujuannya adalah memperbaiki dan mempercantik penampilan fisik seseorang. Indonesia memiliki banyak salon yang tersebar di berbagai propinsi. Masing-masing salon memiliki keunikan dan segmen pasar tersendiri. Begitu pula dengan kota Bandung, bisnis salon berkembang dengan pesat. Hal itu bisa dilihat dari jumlah salon yang ada di Bandung. Adapun jenis-jenis salon yang terdapat di Bandung bisa dilihat pada Tabel 1.1 berikut ini.

\section{TABEL 1.1 SALON DI BANDUNG YANG TERDAFTAR DI BIRO PUSAT STATISTIK TAHUN 2008}

\begin{tabular}{|c|l|c|}
\hline No & \multicolumn{1}{|c|}{ Jenis salon } & Jumlah \\
\hline 1 & $\begin{array}{l}\text { Salon Umum } \\
\text { (pria/wanita) }\end{array}$ & 312 \\
\hline 2 & Salon khusus muslimah & 6 \\
\hline 3 & Salon khusus anak & 5 \\
\hline \multicolumn{2}{|c|}{ Total } & $\mathbf{3 2 1}$ \\
\hline
\end{tabular}

Sumber: www.cafemuslimah.com

Tabel $1.1 \mathrm{di}$ atas berisi jenis salon yang ada di Bandung. Dari tabel tersebut bisa terlihat ada 312 salon umum, yang diperuntukkan bagi pria dan wanita, juga terdapat lima salon khusus untuk anak atau balita, serta terdapat enam salon yang khusus untuk muslimah. Beberapa tahun terakhir ini banyak wanita yang berusaha mencari salon yang diperuntukkan khusus untuk wanita, sehingga wanita yang menggunakan jilbab lebih leluasa dalam melakukan aktifitas perawatan di salon, tanpa khawatir auratnya dilihat oleh prima. Hal ini adalah salah satu alasan yang menyebabkan didirikannya salon muslimah. 
Beberapa salon muslimah yang ada di Bandung bisa dilihat pada Tabel 1.2 berikut ini.

TABEL 1.2

SALON MUSLIMAH DI BANDUNG

\begin{tabular}{|c|c|c|}
\hline No & Nama Salon & Alamat \\
\hline 1 & $\begin{array}{ll}\text { Moz5 } & \text { salon } \\
\text { muslimah } & \end{array}$ & $\begin{array}{l}\text { J1. Tubagus Ismail, } \\
\text { Dago }\end{array}$ \\
\hline 2 & Cyti salon & $\begin{array}{l}\text { Jl. Cilimus } \\
\text { 01/04 - Isola }\end{array}$ \\
\hline 3 & $\begin{array}{l}\text { Humaira salon } \\
\text { muslimah }\end{array}$ & $\begin{array}{l}\text { Jl. Tubagus Ismail } \\
\text { indah }\end{array}$ \\
\hline 4 & $\begin{array}{l}\text { Lu'lu house of } \\
\text { muslimah }\end{array}$ & Cikutra \\
\hline 5 & $\begin{array}{l}\text { Camilla salon } \\
\text { muslimah }\end{array}$ & Gegerkalong girang \\
\hline 6 & $\begin{array}{l}\text { Amirah } \\
\text { muslimah salon }\end{array}$ & Cihampelas \\
\hline
\end{tabular}

Sumber: www.cafemuslimah.com

Bandung memiliki enam salon muslimah yang terletak di beberapa lokasi. Setiap salon memiliki keunikan tersendiri dan daya tarik yang berbeda dibandingkan dengan salon muslimah yang lain. Untuk memulai suatu bisnis salon, perlu diperhatikan apakah salon tersebut memiliki kelebihan dibandingkan dengan salon yang lain, sehingga memberikan manfaat (benefit) baik itu nilai fungsional maupun emosional. Manfaat fungsional pada salon bisa dilihat dari kepuasan yang dirasakan konsumen terhadap jasa yang diberikan salon serta jumlah pengunjung salon pada setiap harinya. Serta manfaat emosionalnya adalah adanya rasa senang yang pada akhirnya akan menciptakan loyalitas. Jumlah pengunjung salon muslimah bisa dilihat pada Tabel 1.3 pada halaman selanjutnya.

TABEL 1.3

JUMLAH PENGUNJUNG SALON
MUSLIMAH DI BANDUNG TAHUN 2005-2008

\begin{tabular}{|l|c|c|c|c|}
\hline \multirow{2}{*}{ Nama Salon } & \multicolumn{4}{|c|}{ Jumlah Pengunjung } \\
\cline { 2 - 5 } & $\mathbf{2 0 0 5}$ & $\mathbf{2 0 0 6}$ & $\mathbf{2 0 0 7}$ & $\mathbf{2 0 0 8}$ \\
\hline $\begin{array}{l}\text { Salon } \\
\text { muslimah } \\
\text { Moz5 }\end{array}$ & - & - & - & 312 \\
\hline Cyti salon & 5556 & 6761 & 7248 & 8424 \\
\hline $\begin{array}{l}\text { Salon } \\
\text { muslimah } \\
\text { Humaira }\end{array}$ & $\mathbf{8 2 1 9}$ & $\mathbf{8 4 6 5}$ & $\mathbf{7 6 1 2}$ & $\mathbf{7 3 2 8}$ \\
\hline $\begin{array}{l}\text { Lu'lu house } \\
\text { of muslimah }\end{array}$ & 7944 & 8397 & 10797 & 12686 \\
\hline
\end{tabular}

\begin{tabular}{|l|c|c|c|c|}
\hline \multirow{2}{*}{ Nama Salon } & \multicolumn{4}{|c|}{ Jumlah Pengunjung } \\
\cline { 2 - 5 } & $\mathbf{2 0 0 5}$ & $\mathbf{2 0 0 6}$ & $\mathbf{2 0 0 7}$ & $\mathbf{2 0 0 8}$ \\
\hline $\begin{array}{l}\text { Salon } \\
\text { muslimah } \\
\text { Camilla }\end{array}$ & 5152 & 5743 & 6761 & 7239 \\
\hline $\begin{array}{l}\text { Salon } \\
\text { muslimah } \\
\text { Amirah }\end{array}$ & 6684 & 8244 & 10476 & 13452 \\
\hline \multicolumn{4}{|c|}{ Sumber: Modifikasi dari berbagai } \\
sumber Tabel 1.3 di atas berisi jumlah \\
\hline
\end{tabular}
pengunjung pada enam salon muslimah yang ada di Bandung. Pada tabel tersebut terlihat pada setiap tahunnya terjadi pertumbuhan jumlah pengunjung pada masing-masing salon muslimah. Tahun 2005 dan 2006 salon yang bertindak sebagai market leader adalah salon Humaira. Walaupun demikan, peningkatan terbesar pada jumlah pengunjung terjadi pada salon muslimah Amirah yaitu hampir sebesar $30 \%$ pada setiap tahunnya, dan Lu'lu house of muslimah salon juga mengalami peningkatan sebesar $17 \%$ pada dua tahun terakhir. Salon muslimah Humaira juga mengalami peningkatan sebesar 3\% pada tahun 2006, persentase penambahan yang paling sedikit dibandingkan salon muslimah lainnya dan mengalami penurunan pada dua tahun berikutnya sebesar $10 \%$.

Pertumbuhan jumlah pengunjung salon muslimah sebagian besar diiringi oleh pertambahan jumlah pengunjung yang membuat member card pada salon yang bersangkutan. Adapun salon muslimah yang telah memiliki member card(kartu anggota) khusus adalah Humaira, Lu'lu house of muslimah dan salon muslimah Amirah. Ketiga salon muslimah ini membuat member card khusus untuk memberikan kemudahan bagi pengunjung dalam transaksinya. Adapun jumlah member pada salon muslimah bisa dilihat pada Tabel 1.4 .

\section{TABEL 1.4 \\ MEMBER SALON MUSLIMAH TAHUN 2005-2008}

\begin{tabular}{|l|c|c|c|c|}
\hline \multirow{2}{*}{ Nama Salon } & \multicolumn{4}{|c|}{ Jumlah Member } \\
\cline { 2 - 5 } & $\mathbf{2 0 0 5}$ & $\mathbf{2 0 0 6}$ & $\mathbf{2 0 0 7}$ & $\mathbf{2 0 0 8}$ \\
\hline $\begin{array}{l}\text { Salon } \\
\text { muslimah } \\
\text { Humaira }\end{array}$ & 1127 & 1274 & 1132 & 997 \\
\hline $\begin{array}{l}\text { Lu'lu house } \\
\text { of muslimah }\end{array}$ & 912 & 1141 & 1307 & 1496 \\
\hline $\begin{array}{l}\text { Salon } \\
\text { muslimah } \\
\text { Amirah }\end{array}$ & 619 & 931 & 1246 & 1317 \\
\hline Subr: & & & & \\
\hline
\end{tabular}

Sumber: Modifikasi dari berbagai sumber 
Tabel 1.4 di atas menunjukan jumlah member yang dimiliki salon muslimah. Penambahan member terbanyak pada setiap tahun terjadi pada salon Amirah, Sedangkan pada tahun 2008 salon muslimah humaira mengalami penurunan jumlah member hampir 12\% dibandingkan dengan tahun sebelumnya. Penurunan jumlah member di salon Humaira pada tiga tahun terakhir ini diindikasikan karena semakin tingginya persaingan pada bisnis salon, semakin bertambanhya salon muslimah yang memberikan keunikan dan pelayanan yang lebih baik, sehingga pengunjung disinyalir berpindah ke salon muslimah lain.

TABEL 1.5

FREKUENSI KUNJUNGAN MEMBER KE SALON HUMAIRA

TAHUN 2006-2008

\begin{tabular}{|c|c|c|c|c|}
\hline \multirow{2}{*}{ Tahun } & \multicolumn{3}{|c|}{ Frekuensi kunjungan } & \multirow{2}{*}{$\begin{array}{c}\text { Jumlah } \\
\text { member }\end{array}$} \\
\cline { 2 - 4 } & $\begin{array}{c}1-4 \\
\text { kali }\end{array}$ & $\begin{array}{c}5-8 \\
\text { kali }\end{array}$ & $\begin{array}{c}9-12 \\
\text { kali }\end{array}$ & \\
\hline 2006 & 676 & 177 & 421 & 1274 \\
\hline 2007 & 699 & 137 & 296 & 1132 \\
\hline 2008 & 566 & 187 & 244 & 997 \\
\hline
\end{tabular}

Sumber: Data dari Salon Humaira

Tabel 1.5 tersebut menunjukan frekuensi kunjungan member ke salon Humaira dari tahun 2006-2008. Dari tabel tersebut terlihat terjadi penurunan jumlah kunjungan pada dua tahun terakhir. Pada tahun 2006 sebanyak 421 member melakukan perawatan di salon Humaira, tetapi tahun 2007 hanya ada 296 member yang melakukan perawatan sebanyak 9 sampai 12 kali dalam satu tahun. Tahun 2008 penurunan kembali terjadi, dan sebanyak 566 member hanya melakukan 1-4 kali perawatan dalam satu tahun.

Survei yang dilakukan pada 30 member salon menunjukan rendahnya loyalitas yang dimiliki oleh member. Frekuensi kunjungan member sangat rendah. 21 member melakukan perawatan tidak lebih dari 2 kali dalam satu bulan. Serta hanya 4 member yang membeli produk yang dijual oleh salon, selain melakukan perawatan. Selain itu member juga jarang merekomendasikan salon Humaira kepada pihak lain. Hal ini dilihat dari hasil survey dari 30 orang member, yang merekomendasikan salon kepada orang lain hanya sebesar 7 orang saja. Dan terkadang member juga masih mencoba perawatan ke salon muslimah lain selain Humaira. Hal ini menunjukan loyalitas yang rendah bagi member salon Humaira. Loyalitas yang rendah juga ditunjukan dengan berkurangnya jumlah member yang mengunjungi salon Humaira.
Upaya yang dilakukan salon Humaira untuk mengatasi penurunan jumlah member dan pengunjung untuk menciptakan pengunjung yang loyal adalah dengan melakukan pembenahan pada beberapa aspek agar dapat menarik minat wanita untuk mengunjungi dan menggunakan jasa salon Humaira. Adapun strategi yang digunakan salon Humaira untuk meningkatkan pangsa pasar dan mempertahankan jumlah member adalah dengan memberikan harga pelajar kepada wanita yang masih bersekolah, memberikan potongan harga bagi pemegang member card, selain itu salon muslimah Humaira juga memberikan pelayanan gratis kepada member disaat mereka berulang tahun.

Strategi lain yang dilakukan Humaira adalah dengan memperbaiki suasana salon agar lebih nyaman, dan mulai menerapkan strategi experiential marketing. Experiential marketing adalah pendekatan yang dilakukan untuk memberikan informasi mengenai produk atau jasa. Adanya experiential marketing, akan mampu membuat pelanggan bisa membedakan produk dan jasa yang satu dengan lainnya karena mereka dapat merasakan dan memperoleh pengalaman secara langsung melalui lima pendekatan (sense, feel, think, act, relate), baik sebelum maupun ketika mereka mengkonsumsi sebuah produk atau jasa. (Adreani :7, Pengaruh experiential Marketing melalui lima pendekatan (sense, feel, think, act dan relate) terhadap loyalitas kunjungan di Mc.D, Surabaya jurnal manajemen pemasaran Vol 2, No 1 tahun 2007).

Adapun penerapan experiential marketing pada salon humaira adalah dengan lebih menekankan pada pengalaman (experience) pengunjung. Untuk menciptakan pengalaman yang baik, Humaira berusaha menciptakan sense yang berkaitan dengan gaya (style) muslimah dalam pengemasan desain salon. Pemilihan warna hijau yang tidak mencolok dalam warna salon dan desain minimalis yang ditampilkan membuat pengunjung merasa betah dan tidak canggung berada di salon. Hal ini bertujuan agar bisa membuat pengunjung merasa nyaman dan betah saat melakukan aktivitas perawatan di salon. Selain itu pegawai dari salon muslimah sendiri mengenakan jilbab sehingga bisa menciptakan ikatan emosi yang dalam kepada pengunjung.

Pihak salon Humaira juga berusaha menciptakan feel yang baik antara pengunjung dengan pegawai salon. Feel dalam hal ini berbeda dengan kesan sensorik, karena dalam hal ini berkaitan dengan suasana hati dan jiwa pengunjung. Untuk menciptakan feel yang baik, pegawai salon Humaira memberikan pelayanan terbaik dimulai dari saat pengunjung datang, 
mempersilahkan masuk dan menawarkan jenis perawatan yang tersedia. Selain itu, pegawai salon juga menjelaskan jenis-jenis perawatan, alokasi waktu yang digunakan dan biaya yang harus dibayarkan pada perawatan tersebut. Pegawai salon humaira berusaha membuat pengunjung merasa nyaman dengan cara melayani dengan ramah, dan berusaha mengerti kebutuhan dari pengunjung salon. Setelah pengunjung memilih perawatan, pengunjung dipersilahkan untuk menunggu di ruang tunggu dan mempersiapkan diri untuk perawatan. Feel yang baik akan menciptakan ikatan yang baik antara pengunjung dengan pegawai, sehingga akan menciptakan kepuasan dan sikap loyal pada pengunjung.

Penerapan sense dan feel yang dilakukan salon Humaira, diharapkan akan mampu menciptakan pemikiran positif (think) pada hati member salon Humaira sehingga diharapkan akan menumbuhkan kesan mendalam dan akhirnya menimbulkan aksi (act) positif dari member dan menciptakan hubungan

\section{KERANGKA PEMIKIRAN}

Strategi pemasaran berkembang dengan cepat, mulai dari strategi pemasaran jasa hingga pemasaran experiential, menurut Hermawan Kartajaya (SWA 2001:44) saat ini ada lima tingkatan pemasaran yang terus berkembang di dunia bisnis.

Pertama, pemasaran komoditas, pada tahap ini tidak ada pembeda antara produk yang satu dengan produk yang lainnya, hargapun tidak bisa ditentukan sendiri karena bergantung pada suplai dan permintaan. Kedua, goods marketing, pemasaran pada tahap ini sudah memperhatikan diferensiasi antar produk dan sudah bisa menentukan harga sendiri. Ketiga, service marketing, dimana konsumen telah membeli produk/jasa dalam satu paket lain seperti layanan sebelum dan sesudah penjualan, pada tahap ini pula konsumen sudah bisa mempertimbangkan tingkat kepuasan mereka. Keempat, experiential marketing, yaitu tahapan pemasaran di lingkungan pasar yang sudah paham dengan service marketing. Pada tahapan ini dilakukan pendekatan dengan menghadirkan pengalaman holistik melalui penggunaan seluruh panca indera. Terakhir adalah transformation marketing, pada tahap ini pemasar tidak hanya menciptakan memori jangka panjang, tetapi bisa melakukan perubahan transformasi secara lebih permanen.

Kondisi sekarang pemasar dituntut menjalankan strategi pemasaran experiential, dimana pasar tidak lagi melakukan permintaan akan barang dan jasa yang berkualitas, tetapi yang baik antara pengguna produk dengan salon(relate).

Schmitt (1999:34) mengemukakan manfaat penerapan experiential marketing adalah untuk membangkitkan kembali merek yang sedang merosot, untuk membedakan satu produk dengan produk pesaing, untuk menciptakan citra dan identitas sebuah perusahaan, untuk mempromosikan inovasi, untuk membujuk percobaan, pembelian dan loyalitas konsumen.

Mengingat pentingnya penerapan experiential marketing dan bagaimana pengaruhnya terhadap loyalitas pengunjung salon Humaira, maka perlu dilakukan penelitian dengan judul "Pengaruh Implementasi Experiential Marketing Terhadap Loyalitas Member Salon Humaira (Survei pada Member Salon Humaira)".

juga manfaat emosional berupa pengalaman tak terlupakan (memorable experience) yang mempererat hubungan konsumen dengan produsen melalui produk yang ditawarkan.

Gagasan pemasaran experiential (experiential marketing) tersebut dikenalkan oleh Bernd H.Schmitt pada tahun 1999. Menurut Schmitt ( 1999:3), ditengah era revolusi pemasaran ini strategi experiential marketing akan menggeser pendekatan tradisional yang menekankan pada fitur dan benefit produk, serta memandang konsumen sebagai sosok yang rasional. Menurutnya pendekatan tradisional tanpa melibatkan unsur emosi dan pengalaman merupakan strategi yang rentan dari peniruan atau penyerangan produk serupa oleh pesaing.

Pendekatan experiential marketing dibentuk guna melengkapi pendekatan tradisional dengan menghadirkan pengalamanpengalaman yang unik, positif dan mengesankan yang membentuk memorable experience bagi konsumen. Pengalaman tak terlupakan tersebut adalah nilai berupa emotional benefit (manfaat emosional) yang ditawarkan sesuai dengan kebutuhan konsumen dan menjadi keunggulan perusahaan yang sulit ditiru oleh pesaing.

Schmitt (1999:60) menjelaskan kerangka kerja konseptual dalam mengelola akumulasi pengalaman pelanggan (experiental marketing) bagi suatu perusahaan. Fokus kerangka kerja (frame work) tersebut dibagi menjadi dua konsep yaitu strategic experiential modules (SMEs) yang merupakan pondasi experiential marketing dan experiences 
providers (ExPros) sebagai alat taktis untuk mengimplementasi experiential marketing.

$$
\text { Experiental modules }
$$

(SMEs)

mendeskripsikan lima tipe tahapan pengalaman yang menjadi bentuk dasar experiential marketing frame work, kelima tipe tersebut adalah sense, feel, think, act dan relate.

a. Sense: Panca indera pelanggan.

Sense Marketing adalah Bagian dari experiential marketing yang di laksanakan untuk mengikat panca indera konsumen dan memberikan kesan keindahan, kesenangan, kecantikan dan kepuasan melalui stimulasi sensori. Adapun sense ini diciptakan melalui Pengalaman yang mengikat panca indera melalui pengemasan desain dan tata letak(Pemilihan unsur warna salon,Suasana di dalam salon, Pemilihan desain dan tata ruang, Kenyamanan atmosfer salon), Pelayanan (Penampilan karyawan, Keramahan karyawan, Kesigapan pegawai salon, Kemudahan dalam pemilihan paket perawatan), faktor lingkungan( Lingkungan disekitar salon, Suasana disekitar salon).

b. Feel: perasaan pelanggan

Feel adalah Kinerja produk/jasa dalam menyentuh perasaan/emosi dengan sasaran membangkitkan pengalaman afektif. Hal ini dilakukan melalui Pengalaman yang mengikat panca indera melalui : (Pemilihan unsur warna salon,Suasana di dalam salon, Pemilihan desain dan tata ruang, Kenyamanan atmosfer salon), Pelayanan (Penampilan karyawan, Keramahan karyawan, Kesigapan pegawai salon, Kemudahan dalam pemilihan paket perawatan), faktor lingkungan( Lingkungan disekitar salon, Suasana disekitar salon).

2. Think: Pemikiran pelanggan

Dengan berpikir (think) dapat merangsang kemampuan intelektual dan kreativitas seseorang. Sebagai contoh penerapan pada salon, yaitu dengan dipasangnya lukisan kaligrafi dan adanya musik islami yang dipasang, sehingga mampu menimbulkan pemikiran positif dari pelanggan salon, serta membuat pelanggan bisa membedakan antara salon Humaira dengan salon lainnya.

3. Act: Aksi yang dilakukan pelanggan

Act berkaitan dengan perilaku yang nyata dan gaya hidup seseorang. Hal ini berhubungan dengan bagaimana membuat orang berbuat sesuatu dan mengekspresikan gaya hidupnya. Pada salon, act ditunjukan dengan desain salon dan jenis perawatan yang bisa menunjukan gaya hidup dari pelanggan. Desain yang berkelas, jenis perawatan beserta range harga yang ada di salon bisa menunjukan gaya hidup seseorang. Jadi 'Act' di sini meliputi perilaku yang nyata atau gaya hidup yang lebih luas.

4. Relate : Hubungan pelanggan dan perusahaan

Relate berkaitan dengan budaya seseorang dan kelompok referensinya yang dapat menciptakan identitas sosial. Seorang pemasar harus mampu menciptakan identitas sosial (generasi, kebangsaan, etnis) bagi pelanggannya dengan produk atau jasa yang ditawarkan. Pada salon, relate dapat ditunjukkan menggunakan simbol budaya dalam desain Web yang mampu mengidentifikasikan kelompok pelanggan tertentu. Desain web yang minimalis, dan dengan icon wanita muslimah yang mengenakan pakaian muslimah dan jilbab merupakan contoh desain dari 'Relate' yang mampu menarik perhatian wanita muslimah untuk mengunjungi salon. Pelanggan salon kebanyakan mempunyai kesamaan berupa jilbab yang dikenakan di tubuh. Mereka menunjukkan kelompok referensi tertentu dengan apa yang dimilikinya.

Experiential providers (ExPros) menjelaskan bagaimana SEMs dapat dibentuk atau disebut juga dengan contact point antara produsen dan konsumen dimana ExPros ini adalah medium yang mampu mengoptimalkan rangsangan SEMs. Media yang digunakan dapat berupa communications, visual/verbal identity, product presence, co-branding, spatial environment, electronic media dan people.

a. Communications : Iklan dan brosur dan pamflet.

Penerapan communications pada salon adalah dengan pemasangan iklan di website yang di update setiap hari, serta adanya brosur dan pamflet yang dibagikan kepada pengunjung, yang berisi tentang promo bulanan, jenis paket perawatan dan harga yang ada di salon Humaira..

b. Visual/Verbal Identity: Nama/logo perusahaan

Visual/Verbal Identity ditunjukkan dengan pemilihan logo dan nama perusahaan (dalam hal ini salon) yang sekiranya bisa menunjukan karakteristik muslimah, dan bisa menggambarkan citra seorang muslimah yang lembut.

c. Product Presence: Tampilan Produk, kemasan, rasa dan lain-lain.

Product Presence pada salon biasanya ditunjukan dengan tampilan salon, pengemasan jenis perawatan di salon, serta keunikan jenis perawatan di salon. Product presence antara salon yang satu dengan salon yang lain biasanya berbeda, sesuai dengan kebijakan dari pengelola salon. 
d. Co-Branding: Event Marketing, Sponshorship

Co-Branding sering diterapkan di salonsalon dalam bentuk pengadaan event yang dilaksanakan pada periode dan moment tertentu. Misalnya pada bulan ramadhan, salon muslimah banyak mengadakan event marketing seperti kursus kecantikan muslimah atau kursus menggunakan jilbab cantik.

e. Spatial Environment: Warna, Design lingkungan dan lain-lain

Spatial environment sering ditunjukan dengan pemilihan warna, design yang mencerminkan jati diri atau karakter yang ingin ditunjukan kepada pelanggan. Pada salon Spatial environment ditunjukan dengan pemilihan warna dan design salon yang menunjukan ciri khasnya, serta menampilkan keunikan dan bertujuan untuk menarik minat konsumen untuk mencoba menggunakan jasa salon.

f. Electronic Media: Web Sites

Web sites sering digunakan untuk memperkenalkan produk atau jasa kepada masyarakat umum. Kemudahan dalam mengakses web sites dan perkembangan teknologi membuat banyak perusahaan yang menggunakan web sites untuk memperkenalkan produk atau jasa kepada masyarakat. Begitu pula dengan salon. Banyak salon yang menggunakan web sites untuk memperkenalkan salon, mempromosikan jenis pelayanan dan fasilitas yang dapat dimanfaatkan oleh pengunjung.

g. People: Pelayan, Customer Service dan lainlain.

Pelayan, Customer Service, sangat mempengaruhi keberhasilan suatu perusahaan atau badan usaha. Pelayanan yang baik dan memuaskan, serta adanya pelayanan yang baik dari Customer Service bisa menciptakan loyalitas bagi konsumen. Begitu pula pada salon. Pegawai salon dibekali keterampilan khusus yang sesuai dengan keahlian mereka, sehingga bisa memuaskan pengunjung. Selain itu adanya pihak pengelola yang bersedia menampung ide dan saran dari pengunjung, yang bisa segera menindaklanjuti kritik dan saran dari pengunjung.

Keberhasilan experiential marketing melaui strategic experiential modules yang diwujudkan dengan Experiential Providers di atas tergantung pada usaha produsen dalam mengemas produk/jasanya secara emosional. Menurut Rolf Jensen (SWA, 2001:53) kecenderungan para pemasar mengemas emosi secara komersial telah mendorong transisi ke dream society, yaitu suatu bentuk masyarakat yang membentuk emotional market (pasar dimana konsumen tidak semata membeli produk, melainkan gaya hidup, petualangan, cinta dan persahabatan, kedamaian serta kepercayaan). Sementara itu, menurut Scott Robinette dan Claire Brand (2006:12) dalam emotion marketing terdapat rantai nilai yang memandang konsumen tidak hanya dari segi rasional tetapi juga emosional, nilai-nilai tersebut dikenal dengan teori bintang nilai (Value Star) yang terdiri dari Money dan Product sebagai nilai rasional serta Equity, Experience dan Energy sebagai nilai emosional. Rational Value menjelaskan nilai yang diterima konsumen pada setiap penggunaan produk dan jasa serta membandingkannya dengan nilai uang (rasional), sedangkan emotional value menjelaskan nilai yang diterima konsumen dari sudut ekuitas, pengalaman dan energi.

Nilai ekuitas menurut Scott (2006:44) adalah segala sesuatu yang diterima konsumen atas dasar kepercayaan yang dibangun perusahaan melalui identitas dan image mereknya. Ketika perusahaan memenuhi janji atas brand promises yang dibuatnya, maka perusahaan telah membentuk identitas dan kepribadian merek yang memberikan aspirasi positif bagi konsumen.

Nilai lain yang dibentuk melalui emosional adalah pengalaman. Scott (2006:64) menegaskan bahwa pengalaman adalah "the collection of points at wich companies and consumers exchange sensory stimuli, information, and emotion." Menurutnya pengalaman adalah sekumpulan peristiwa ketika perusahaan melakukan transaksi, pertukaran informasi, dan emosi yang terjadi antara konsumen dengan produsen dimana konsumen memperolehnya melalui:

a. Pengalaman dengan produk

b. Pengalaman dengan lingkungan

c. Pengalaman komunikasi

d. Pengalaman dalam pelayanan konsumen

e. Pengalaman dalam kegiatan (event).

Kumpulan pengalaman di atas merupakan dasar pembentukan kepercayaan yang dibangun perusahaan terhadap konsumennya.

Selain ekuitas dan experience, nilai lain yang membentuk emotional value adalah energy. Nilai energi adalah segala sesuatu yang berhubungan dengan waktu atau seberapa lama waktu yang diperlukan konsumen untuk memperoleh produk/jasa tertentu. Inti dari nilai energi adalah memberikan kemudahan dan membuat segala sesuatunya lebih cepat bagi konsumen hingga konsumen mendapatkan pengalaman tak terlupakan. Hal ini merupakan 
salah satu faktor yang mendorong terciptanya kepuasan bagi konsumen dan mewujudkan loyalitas bagi perusahaan. Menurut Oliver (2007:392) loyalitas konsumen didefinisikan sebagai:

Suatu komitmen untuk bertahan secara mendalam dengan melakukan pembelian ulang atau berlangganan kembali dengan produk atau jasa yang terpilih secara konsisten dimasa yang akan datang, meskipun pengaruh situasi dan usaha-usaha pemasaran mempunyai potensi untuk menyebabkan perubahan perilaku.

Dari definisi di atas dapat dijelaskan bahwa loyalitas lebih mengacu pada wujud perilaku dari unit-unit pengambilan keputusan untuk melakukan pembelian secara terus menerus terhadap barang/ jasa suatu perusahaan yang dipilih.

$$
\text { Adapun Griffin }
$$

mengemukakan karakteristik pelanggan yang loyal adalah melakukan pembelian ulang (repeat purchases) terhadap barang/jasa atau perusahaan yang menjadi pilihannya, memiliki sifat retention yaitu tidak mudah terpengaruh atau tertarik dengan penawaran barang/jasa atau perusahaan lain dan mempunyai sifat referrals artinya bila terjadi ketidak puasan dalam proses mengkonsumsi barang/jasa, fenomena ini tidak diceritakannya kepada pihak lain, tetapi dijadikan bahan masukan atau saran kepada perusahaan.

Perilaku pelanggan yang loyal seperti diuraikan di atas tidak terjadi secara otomatis dalam waktu singkat, melainkan melalui suatu proses tahapan tertentu. Hill (2006:60) menyatakan bahwa tahapan atau tingkatan loyalitas pelanggan secara ranking dimulai dari suspect, prospect, first time customer, repeat customer client, advocat sampai dengan partners, dimana:

a. Suspect adalah semua orang yang diyakini akan membeli (membutuhkan) barang/jasa, tetapi belum memiliki informasi tentang barang/jasa perusahaan.

b. Prospect adalah orang yang memiliki kebutuhan, memiliki daya beli dan memiliki informasi dari rekomendasi word of mouth

c. First time customers adalah pelanggan yang membeli untuk pertama kalinya, mereka masih menjadi konsumen baru

d. Repeat customers adalah pelanggan yang telah melakukan pembelian dua kali atau lebih terhadap barang/jasa atau perusahaan yang sama.

e. Client adalah pelanggan yang telah membeli semua barang/jasa yang dibutuhkannya dan yang ditawarkan perusahaan secara teratur dan hubungan ini berlangsung lama, dan mereka memiliki sifat retention.

f. Advocat adalah para client yang sudah merasakan kepuasan, sehingga diceritakannya kepada pihak lain sebagai pemberi rekomendasi word of mouth, dan ikut serta memasarkan barang/jasa perusahaan.

g. Partners merupakan suatu kekuatan dari hubungan antara pelanggan dan supplier yang berkelanjutan sebab keduanya melihat adanya manfaat bersama.

Grifin (2002:31) mengemukakan Indikator dari loyalitas yang kuat adalah:
a. Repeation
b. Purchase accross product line
c. Retention
d. Recommendation

Selanjutnya kerangka pemikiran ini dijelaskan dalam gambar pada halaman selanjutnya: 


\section{StrategiC}

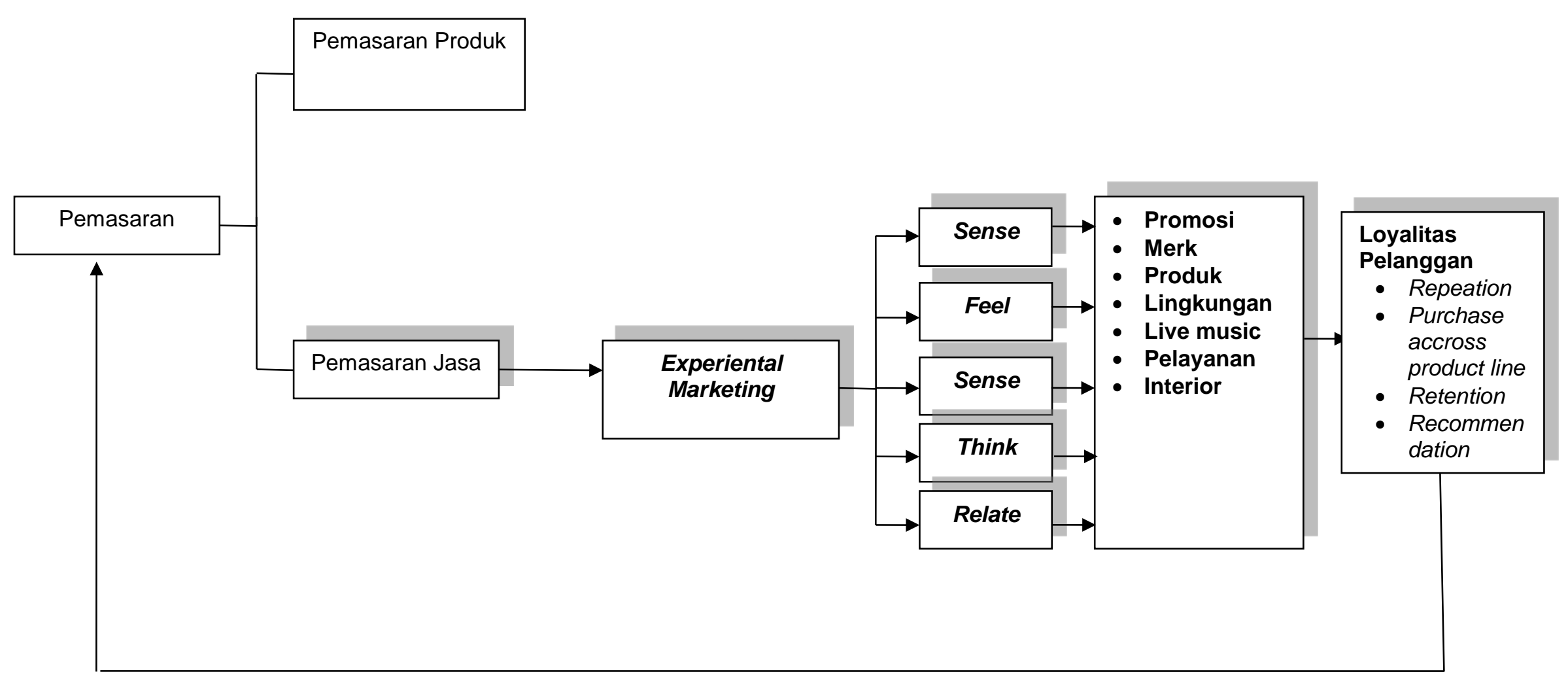

GAMBAR 1.1

KERANGKA PEMIKIRAN

PENGARUH IMPLEMENTASI EXPERIENTIAL MARKETING TERHADAP LOYALITAS 


\section{METODE PENELITIAN}

Berdasarkan tingkat penjelasan dan bidang penelitian, maka jenis penelitian ini adalah penelitian deskriptif dan verifikatif. Menurut Sugiyono (2008:11) menjelaskan bahwa, "penelitian deskriptif adalah penelitian yang dilakukan untuk mengetahui nilai variabel mandiri, baik satu variabel atau lebih tanpa membuat perbandingan atau menghubungkan dengan variabel yang lain". Penelitian deskriptif disini bertujuan untuk memperoleh deskripsi atau gambaran mengenai pengaruh implementasi experiential merketing dan bagaimana loyalitas pengunjung Salon Humaira.

Berdasarkan jenis penelitiannya yaitu penelitian deskriptif dan verifikatif yang dilaksanakan melalui pengumpulan data di lapangan, maka metode yang digunakan dalam penelitian ini adalah metode descriptive survey dan metode explanatory survey. Menurut Kerlinger yang dikutip oleh Sugiyono (2008:7), bahwa yang dimaksud dengan metode survei adalah:

Metode penelitian yang dilakukan pada populasi besar maupun kecil, tetapi data yang dipelajari adalah data dari sampel yang diambil dari populasi tersebut, sehingga ditemukan kejadian-kejadian relatif, distribusi, dan hubunganhubungan antar variabel sosiologis maupun psikologis.

\section{HASIL DAN PEMBAHASAN}

Secara keseluruhan, gambaran experiential marketing di salon Humaira dilakukan melalui pendekatan lima dimensi, yaitu sense, feel, think, act dan relate. Masingmasing dimensi memberikan gambaran produk/jasa yang ditawarkan, mulai dari promosi dan diskon khusus, variasi produk/perawatan yang ditawarkan, keadaan di dalam salon, desain interior dan eksterior ruangan , pelaksanaan acara kursus kecantikan dan keramahan serta kesopanan karyawan dalam melakukan melayani konsumen.

Adapun Skor ideal Experiental Marketing untuk 55 item pertanyaan adalah 28.600. Perolehan skor berdasarkan hasil pengolahan data pada variabel Experiental Marketing adalah 22.623, dengan perhitungan sebagai berikut: Mencari Skor Ideal Expriental Marketing :
Skor Ideal $=$ Skor Tertinggi $\mathrm{x}$ Jumlah Butir Item x Jumlah Member

Skor Ideal $=5 \times 44 \times 130=28.600$

Mencari Skor Terendah Expriental Marketing

Skor Terendah $=$ Skor Terendah $\mathrm{x}$ Jumlah Butir Item x Jumlah Member

Skor Terendah $=1 \times 44 \times 130=5.720$

Mencari Panjang Interval

Panjang Interval Kelas $=$ Skor Ideal :

Banyak Interval

5.720

Panjang Interval Kelas $=28.600: 5=$

Nilai 22.623 sesuai dengan data penelitian yaitu berada dalam kategori cukup dan tinggi, dapat dikatakan termasuk dalam kategori tinggi. Jadi sebagian besar member salon humaira menggolongkan experiental marketing pada salon humaira kedalam kategori tinggi yang artinya penerapan sense, feel, think, act dan relate di salon humaira telah berjalan dengan baik.

Tingginya experiential marketing di salon Humaira bisa dilihat dari perolehan skor yang didapat dari pengolahan data hasil penelitian dari sub-sub dimensi sense, feel, think, act dan relate berikut ini.

Sense dalam konteks Experiential Marketing adalah kelima indera sebagai alat untuk merasakan produk dan jasa yang ditawarkan. Sense yang ditawarkan harus distimulus dengan benar agar dapat memberikan sesuatu yang mengesankan dan experiential. Sedangkan skor tertinggi yaitu pada item tata ruang letak, dengan skor 514 yang terdiri dari 4,6\% member menyatakan tidak baik, $13,8 \%$ member menyatakan cukup baik, 63,1\% member menyatakan baik, dan $18,5 \%$ member menyatakan sangat baik. Hal ini memberikan gambaran bahwa member yang datang ke salon Humaira dapat melihat letak ruangan salon yang tersusun dengan baik dan rapi, sehingga penglihatan member dapat distimuli dengan baik dengan apa yang dilihat dan dirasakan sehingga member merasa nyaman dan betah melakukan perawatan di salon Humaira. Stimuli dalam hal ini adalah dengan memaksimalkan panca indra dalam menarik emosi pelanggan.

Feel artinya mengusahakan pelanggan agar merasa feel good agar dapat menimbulkan pikiran dan opini yang positif. Perasaan di sini sangatlah berbeda dengan kesan sensorik karena hal ini berkaitan dengan suasana hati dan emosi jiwa seseorang. Ini bukan sekedar menyangkut 
keindahan, tetapi suasana hati dan emosi jiwa yang mampu membangkitkan kebahagiaan atau bahkan kesedihan.

Skor terendah dari tanggapan member terhadap feel dalam program experiental marketing yaitu perasaan pada saat sambutan yaitu 457 yang terdiri dari 10,8\% member menyatakan tidak senang, 38,5\% member menyatakan cukup senang, 39,2\% member menyatakan senang, dan $11,5 \%$ member menyatakan sangat senang. Hal ini disebabkan kurang ramahnya karyawan pada saat menyambut member yang baru datang, sehingga member merasa kurang tergugah perasaannya sehingga tidak merasakan feel yang baik. Keramahan dalam menyambut member yang baru datang perlu diperbaiki lagi, karena keramahan bisa menciptakan feel positif yang pada akhirnya bisa membuat member merasa nyaman.

Teori pemasaran Experience dikatakan bahwa feeling yang bagus akan membawa pelanggan mampu berfikir positif sehingga memberikan opini yang bagus terhadap produk dan service perusahaan. Think dapat digunakan untuk melakukan promosi salon. Diketahui bahwa skor terendah dari tanggapan member terhadap think dalam program experiental marketing yaitu pelayanan karyawan yaitu 462 yang terdiri dari $0,8 \%$ member menyatakan sangat negatif, 3,8\% member menyatakan negatif, 32,3\% member menyatakan cukup, $50,0 \%$ member menyatakan positif, dan $13,3 \%$ menyatakan sangat positif. Walaupun lebih dari $50 \%$ member menyatakan pelayanan positif, akan tetapi masih ada member yang merasa kurang puas akan pelayanan yang diberikan salon Humaira, dengan kata lain pelayanan kepada member harus ditingkatkan agar member bisa merasa lebih puas dan merasa nyaman dalam melakukan perawatan sehingga bisa menimbulkan experience yang positif.

Konsumen akan bertindak (melakukan pembelian) karena pengaruh luar dan opini dari dalam, tugas experiential marketer adalah menggabungkan pengaruh eksternal dengan feel dan think pelanggan untuk dijadikan suatu aksi yang akan menghasilkan kenangan tak terlupakan (experiential). Act marketing, ditujukan untuk mempengaruhi perilaku, gaya hidup dan suatu bentuk interaksi dengan konsumen.
Diketahui bahwa skor terendah dari tanggapan member terhadap Act dalam program experiental marketing yaitu item mengikuti event yaitu 472 yang terdiri dari $3,1 \%$ member menyatakan jarang mengikuti event yang diadakan salon Humaira, 43,1\% member menyatakan cukup sering mengikuti event, 41,5\% member menyatakan sering, dan $12,3 \%$ member menyatakan sangat sering mengikuti event yang diadakan salon Humaira. Masih terdapat beberapa persen member jarang mengikuti event yang diadakan oleh salon humaira, hal ini di karenakan member mengganggap event yang diadakan tersebut kurang menarik, sehingga tidak menimbulkan kesan positif.

Relate merupakan hubungan atau gaya hidup yang dirasakan pelanggan, baik itu hubungan terhadap perusahaan ataupun hubungan sesama komunitas pengguna produk/jasa perusahaan. Relate marketing, merupakan kombinasi sense, feel dan think marketing yang bertujuan mengaitkan individu dengan sesuatu yang berada di luar dirinya.

Diketahui bahwa skor terendah dari tanggapan member terhadap Relate dalam program experiental marketing yaitu item pertanyaan memperoleh banyak teman di salon Humaira yaitu 457 yang terdiri dari 1,5\% member menyatakan sangat tidak setuju bahwa member memperoleh banyak teman, 10,8\% member menyatakan tidak setuju, $27,7 \%$ member menyatakan cukup setuju, 45,5\% member menyatakan setuju, dan 45,5\% member menyatakan sangat setuju. Hal ini karena member menganggap salon Humaira hanya tempat untuk membuat tubuh rileks dan merawat badan, bukan sebagai tempat mecari teman. Namun mayoritas member telah menjadikan Humaira sebagai tempat untuk mencari teman. Hal ini menunjukan penerapan relate yang baik di salon Humaira.

Secara keseluruhan variabel (Y) tentang loyalitas pelanggan dapat diketahui kedudukannya, berdasarkan skor yang didapat dari rekapitulasi data, di mana nilai-nilai tersebut dibandingkan dengan kriteria skor standar, yang didapat melalui perhitungan skor ideal (kriterium) dan skor terkecil, sehingga melalui skor standar tersebut dapat diketahui daerah kontinum yang menunjukkan wilayah ideal dari variabel $(\mathrm{Y})$, hal tersebut dapat dicari 
dengan rumus menurut Sugiyono (2008:135), sebagai berikut

Mencari Skor Ideal loyalitas Pelanggan :

Skor Ideal $=$ Skor Tertinggi $\mathrm{x}$ Jumlah

Butir Item x Jumlah Member

Skor Ideal $=5 \times 11 \times 130=7.150$

Mencari Skor Terendah Loyalitas Pelanggan

Skor Terendah $=$ Skor Terendah $\mathrm{x}$ Jumlah Butir Item x Jumlah Member

Skor Terendah $=1 \times 11 \times 130=1.430$

Mencari Panjang Interval

Panjang Interval Kelas $=$ Skor Ideal :

Banyak Interval

Panjang Interval Kelas $=7.150: 5=$

1.430

Skor ideal loyalitas Pelanggan adalah

untuk 11 item pertanyaan. Perolehan skor berdasarkan hasil pengolahan data pada variabel loyalitas pelanggan adalah 5.386. Nilai 5.386 sesuai dengan data penelitian yaitu termasuk dalam kategori cukup dan tinggi, dapat dikatakan termasuk dalam kategori tinggi. Jadi sebagian besar member salon humaira dapat digolongkan sebagai member yang cukup loyal. Artinya penerapan sense, feel, think, act dan relate di salon humaira telah berjalan dengan baik, sehingga loyalitas terbentuk dengan baik pula. Akan tetapi masih perlu diadakan perbaikan, karena masih terdapat beberapa dimensi yang perolehan skornya dibawah skor ideal.

Experiential marketing yang sangat berpengaruh terhadap loyalitas adalah think. Sedangkan pengaruh langsung terendah dari program Experiental Marketing terhadap loyalitas pelanggan adalah feel yaitu sebesar $3,1 \%$. Pengaruh feel secara tidak langsung terhadap loyalitas pelanggan melalui sense sebesar $2,1 \%$, melalui think sebesar 2,9\%, melalui act sebesar $2,2 \%$ dan melalui relate sebesar $2,6 \%$. Secara umum think berpengaruh terhadap loyalitas pelanggan.

Berdasarkan hasil perhitungan di atas dapat diketahui bahwa pengaruh program experiental marketing terhadap loyalitas pelanggan adalah sebesar 0,678, sedangkan koefisien jalur variabel lain di luar variabel program experiental marketing dimensi sense, feel,think, act, dan relate. Hal tersebut berarti bahwa dimensi sense, feel, think,act dan relate bersama-sama mempengaruhi nilai pelanggan sebesar $69,9 \%$ dan sisanya sebesar $(0,301)^{2}=$
$0,906 \mathrm{x} 100 \%=9,06 \%$ dipengaruhi oleh variabel lain.

\section{KESIMPULAN}

Berdasarkan hasil penelitian yang dilakukan oleh peneliti melalui analisis deskriptif dan verifikatif dengan menggunakan path analysis, maka berdasarkan penelitian tersebut dapat diambil kesimpulan sebagai berikut:

1. Experiential marketing pada salon Humaira Tubagus Ismail Indah menunjukkan bahwa pada dimensi sense ternyata tata letak ruangan salon dinilai member paling menyentuh panca indera, di mana salon Humaira menawarkan tata letak ruangan salon yang menarik dan teratur, sehingga dirasakan yang paling menyentuh panca indera pelanggan. Pada dimensi feel, yang paling menggugah perasaan member adalah desain interior dari salon yang tampak melalui bangunan dan dekorasi salon yang membuat member merasa senang dan nyaman berada di salon. Keramahan dan ruang perawatan yang bersih serta nyaman dinilai paling tinggi dalam dimensi think, di mana keramahan dan ruangan perawatan yang bersih sangat menonjol dan dinilai paling baik sehingga member memberikan penilaian positif. Sedangkan pada dimensi act ternyata alasan utama pelanggan berkunjung kembali ke salon Humaira adalah karena ingin melakukan perawatan ulang, karena member merasa puas dengan perawatan sebelumnya sehingga ingin melakukan perawatan kembali. Pada dimensi relate, pergaulan dengan sesama member dinilai paling tinggi karena banyak member yang telah menjadikan salon Humaira sebagai komunitas dan tempat berkumpul serta bergaul dengan sesama member.

2. Loyalitas member salon Humaira yang diukur melalui dimensi repeation, menunjukkan bahwa keinginan untuk mencoba jenis perawatan lain selain yang sering dilakukan merupakan indikator yang tertinggi. Pada dimensi recomendation dan kekebalan terhadap produk pesaing, yang mendapatkan penilaian tertinggi adalah indikator ingin kembali mengunjungi salon Humaira.

3. Experiential marketing berpengaruh signifikan terhadap loyalitas member salon 
Humaira. Hal ini menunjukkan bahwa semakin tinggi experiential marketing maka akan semakin tinggi loyalitas member salon Humaira.

\section{DAFTAR PUSTAKA}

Aaker, D.A, (2004), “Building Strong Brands”, United Kingdom: Free Press Business

Arikunto, Suharsimi. (2004). Prosedur Penelitian, Jakarta: Penerbit Rineka Cipta.

Brown, Stanley A., (2006), Customer Relationship Management: A Strategic Imperative in the World of e-Business. Canada: John Wiley \& Sons.

Buchari Alma, (2008), Manajemen Pemasaran dan Pemasaran Jasa. Bandung: Alfabeta

Diana LaSalle dan Terry A.Britton, 2008, Turning Ordinary Products Into Extraordinary Experience, Boston: Harvard Business School Press

Fandy Tjiptono, (2008). Strategi Pemasaran, Yogyakarta: Penerbit Andi

Griffin, Jill, 2008, Customer Loyalty How To Earn It, How To Keep it. Singapore : Lexington Books.

Griffin, Jill, 2005, customer Loyalty, menumbuhkan\& mempertahankan kesetiaan pelanggan. Jakarta: Erlangga

Griffin, R.W. dan Elbert, R.J. (2007). Bisnis, Jakarta: Prenhallindo

Harun Al Rasyid, (1994), Teknik Penarikan Sampel dan Penyusunan Skala. Program Pasca Sarjana, Bandung: Universitas Padjadjaran.

Hermawan, Asep, (2006), Penelitian Bisnis Paradigma Kualitatif, Jakarta: PT Gramedia Widia Sarana Indonesia.

Hill, Nigels, (2006), Handbook of Customer Satisfaction Measurement, Hampshire England: Gower Publishing Limited.
Husein Umar, 2008. Metode Penelitian untuk Skripsi dan Tesis Bisnis Edisi 2. Jakarta: PT Raja Grafindo Persada.

H, Schmitt, Bernd, (1999), Experiential Marketing : How to get customer to sense, feel, think, act and relate to your Company and Brand, The free Press : New York

H, Schmitt, Bernd, at all, (2004), There's No Business That Not Show Business: Marketing In An Experiences Culture, Prentice Hall: New York

Kartajaya, Hermawan, et.al, (2007). MarkPlus on Strategy: 12 Tahun perjalanan MarkPlus\&Co Membangun Strategi Perusahaan. Jakarta: PT Gramedia Pustaka Utama.

Kertajaya, Hermawan. (2003), Marketing Plus: Siasat Memenangkan Persaingan Global. Jakarta: penerbit PT. Gramedia pustaka utama.

Kotler, Phillip., (2008), Marketing Management 11ed, New Jersey: Prentice Hall Inc.

Kotler, Philip dan Gary Amstrong, (2008), Manajemen Pemasaran Edisi 12. Jakarta: Indeks

Kotler, Philip dan Keller Kevin Lane, (2007), "Marketing Management", by Pearson Education Inc., Upper Saddle River, New Jersey.

Lupiyoadi, Rambat, A. Hamdoni, 2006. Manajemen Pemasaran Jasa, Salemba Empat, Jakarta.

Oliver, Richard L., (2007), Satisfaction, A Behavioral Perspective On The Customer, New York: McGraw Hill.

Ratih Hurriyati, 2005. Manajemen Pemasaran Jasa dan Loyalitas, Alfabeta, Bandung

Riduwan dan Engkos Achmad Kuncoro, (2008), Cara Menggunakan dan Memakai Analisis Jalur (Path Analysis). Bandung: Alfabeta.

Ronny Kountur, (2007), Metode Penelitian Untuk Penulisan Skripsi dan Tesis. Jakarta: PPM.

Robinette, Scott \& Brand, Claire, 2006, Emotion Marketing, The Hallmark Way of Winning Customers For Live. McGraw-Hill

Sekaran, Uma, (2006), Research Methods For Business, Jakarta: Salemba Empat. 
Simamora Bilson, (2005), Analisis Multivariat

Pemasaran, Jakarta: Gramedia Pustaka Utama

Singarimbun Masri dan Sofyan Effendi, (2007), Metode Penelitian Survey, Jakarta: LP3s.

Smilansky, Shaz, (2009), Experiential Marketing: A Practical guide to interactive brand experiences, Kogan Page: London

Sugiyono, (2008), Metode Penelitian Bisnis, Alfabeta : Bandung.

Smith, Shaun dan Wheeler, Joe, (2002), Managing The Customer Experience, Prentice Hall: New York

Suharsimi Arikunto, (2006), Prosedur Penelitian Suatu Pendekatan Praktik, Rineka Cipta :Jakarta

Umar, Husein. (2008). Metode Riset Bisnis, Jakarta: Penerbit PT Gramedia Pustaka Utama

Yazid. (2005). Pemasaran Jasa: Konsep dan Implementasi. Yogyakarta: Ekonisia FE UII.

Zeithaml, Valarie A. dan Bitner, Mary Jo., (2006), Service Marketing $2^{\text {nd }}$ edition: Integrating Customer Focus., New York: McGraw Hill Inc.

Zhoriva Yusuf, Eva dan Lesley Williams. (2007). Manajemen Pemasaran Studi Kasus Indonesia. Jakarta: PPM.

Zikmund, William G. et.al., (2003), Customer Relationship Management: Integrating Marketing Strategy and Information Technology, New Jersey, JohnWiley and Sons.

Website Internet:

www.business-minds.com

www.cafemuslimah.com

www.buildyourowngarage.com

www.digilib.petra.ac.id

www.ft-ph.com

www.google.com

www.Hermawan.Net

www.jurnalmahasiswafeunair.com

www.joesessays.com

www.marketing.co.id

www.meetschmitt.com

www.perpustakaanunikaatmajaya.com

www.puslit.petra.ac.id/journals/marketing

www.universitaskatolikwidyamandala.com www.wikipedia.com

Penelitian Terdahulu:

Cepy Trian Sudrajat. Pengaruh Citra Merek dan Harga terhadap Loyalitas Pelanggan Sepatu Olah Raga Nike. (2008)

Christina Rahardja. Studi experiential marketing di Timezone Plasa Tunjungan Surabaya. 2008

Dini Rismalati. Pengaruh sense dan feel pada experiental marketing terhadap brand identity serta implikasinya pada costumer brand relationship program acara reality show AFI. 2005

Sansan Ariestana. Pengaruh event and experience melalui program eiger climbing center terhadap loyalitas pelanggan. 2008

Ulhaq. Pengaruh Sense dan Feel dalam Experiential Marketing terhadap Brand Identity Serta Implikasinya pada Customer Brand Relationship. 2008

\section{Jurnal}

Adriani. Pengaruh experiential Marketing melalui lima pendekatan (sense, feel, think, act dan relate) terhadap loyalitas kunjungan di Mc.D, Surabaya. Jurnal Manajemen Pemasaran Vol 2 NO 1, tahun 2007

Agus Rahayu. Pengaruh experiential marketing dan emotional value terhadap loyalitas pelanggan restoran dan cafe, Bandung. Jurnal Manajemen Bisnis: 2003

Fajrianthi. Strategi Perluasan Merek dan Loyalitas Konsumen. Jurnal Universitas Airlangga Desember Vol 7 no 3, tahun 2005)

Hamzah Amir. Analisis experiential marketing dan brand truth terhadap loyalitas merek Mentari. STEKPI:2009

Hallowel Roger. Jurnal service management, tahun 2006 vol 7 no 4, halaman 27-52.

Lili Adi Wibowo. Pengaruh experiential marketing dan emotional value terhadap loyalitas pelanggan cafe dan resto di kawasan cihideung, Lembang, Bandung. Jurnal Ilmiah Agustus vol 4 No 8, tahun 2004 
Yuliastuti. Pengaruh penerapan experiential marketing terhadap kepuasan dan dampaknya pada niat membeli ulang di Mc. D Tunjungan Plaza dan Plaza Surabaya. FE UNAIR: 2005 